\title{
Depression and anxiety disorder among epileptic people at Amanuel Specialized Mental Hospital, Addis Ababa, Ethiopia
}

\author{
Minale Tareke Tegegne ${ }^{1 *}$, Tilahun Belete Mossie ${ }^{2}$, Andargie Abate Awoke ${ }^{1}$, Ashagre Molla Assaye ${ }^{3}$,
} Belete Temitm Gebrie ${ }^{4}$ and Desalegn Asmare Eshetu ${ }^{5}$

\begin{abstract}
Background: Although depression and anxiety disorders are very common in people with epilepsy; there are no studies that assessed the magnitude and associated factors among epileptic people in Ethiopia. Therefore, this study determined prevalence and associated factors of depression and anxiety disorders in people with epilepsy.

Method: An institution based cross-sectional study was conducted from April to May, 2013, among 423 people with epilepsy from the outpatient department of Amanuel Mental Specialized Hospital. Depression and anxiety were assessed using the Hospital Anxiety and Depression Scale. Logistic regression analysis was used to assess predictors of depression and anxiety.

Results: The prevalence of anxiety and depression among epileptic people were 33.5 and $32.8 \%$, respectively. Monthly income, frequency of seizure and side effects of anti convulsants were found to be significantly associated with both depression and anxiety. Being divorced/widowed was associated with anxiety while using poly-therapy of anti convulsants, perceived stigma, and inability to read or write were associated with depression.

Conclusion: The prevalence of co-morbid anxiety and depression was found to be high among people with epilepsy. Early identification of co-morbid depression and anxiety in people with epilepsy and managing epilepsy to become seizure free should be of great concern for health care providers.
\end{abstract}

\section{Background}

Epilepsy is a common neurological condition characterized by recurrent and unpredictable seizures associated with significant psychological and social consequences. More than eighty percent of 50 million people living with epilepsy (PWE) worldwide reside in low-income regions where human and technological resources for health care are extremely limited. Although epilepsy is more likely to be diagnosed in childhood or elder years, it is not confined to any age group, sex or race. Frequent seizures may cause difficulties in important areas of life (at school or the workplace), as well as sometimes hindering the development of new friendships and relationships. Fortunately, epilepsy can be managed with antiepileptic

\footnotetext{
* Correspondence: minale23@gmail.com

${ }^{1}$ College of Medicine and Health Science, Bahir Dar University, Bahir Dar, Ethiopia

Full list of author information is available at the end of the article
}

medications and more than 70 percent of people become seizure-free with treatment [1-3].

Depression is characterized by loss of interest, depressed mood, disturbance of sleep, problem in appetite and psychomotor activity, difficulty to concentrate or make decision, guilty or sinful feeling, easily tiredness and recurring thoughts of death or suicide [4]. Anxiety is the presence of fear or apprehension that is out of proportion to the context of the life situation. An anxiety disorder can be expressed in different ways such as uncontrollable worry, intense fear (phobias or panic attacks) or upsetting dreams or flashbacks of a traumatic event $[4,5]$.

Depression and anxiety disorders are very common in people with epilepsy. The altered brain activity that causes epileptic seizures can lead to depressive moods and the stress of living with a chronic condition can worsen feelings of depression and anxiety. As a consequence, epilepsy
Ciomed Central

(C) 2015 Tegegne et al. Open Access This article is distributed under the terms of the Creative Commons Attribution 4.0 International License (http://creativecommons.org/licenses/by/4.0/), which permits unrestricted use, distribution, and reproduction in any medium, provided you give appropriate credit to the original author(s) and the source, provide a link to the Creative Commons license, and indicate if changes were made. The Creative Commons Public Domain Dedication waiver (http://creativecommons.org/publicdomain/zero/1.0/) applies to the data made available in this article, unless otherwise stated. 
may be more difficult to manage as depression is sometimes known to make seizures more frequent and can decrease the motivation to manage epilepsy effectively [6].

People with epilepsy experience depression at two to three times the rate of the general population [7]. Literatures reported a strong link between epilepsy, depression and anxiety disorders. The disorders can be aggravated or developed following being diagnosed for epilepsy; or as a consequence of living with epilepsy. Structural brain abnormalities, monoamine pathways, cerebral glucose metabolism and the hypothalamic-pituitary-adrenal axis are also associated with the pathogenesis of depression in people with epilepsy. But once they are diagnosed, depression and anxiety disorders can be safely and effectively treated at the same time as epilepsy. Treatments for mental health conditions can greatly improve quality of life and can reduce the frequency and impact of seizures $[8,9]$.

According to different world wide literatures the magnitude of depression and anxiety disorder among adult epileptic people had a varied figure. The presence of depressive symptoms accounted $20 \%$ in Thailand [10], $25 \%$ in India [11], 24 to $32 \%$ in Brazil [12, 13], 38 and $60 \%$ at China and Pakistan, respectively [14, 15 ]; where as it was $25.5 \%$ in Egypt [16]. In addition, anxiety disorders were reported among $39 \%$ of Thailand subjects [10], 33 to $39 \%$ of Brazilian participants [12, 13], $30 \%$ of Chinese [14] and $47 \%$ of Egyptians [16].

There are multiple risk factors associated with increased risk of psychiatric problems in epilepsy which can be broadly divided into biological (e.g. type and severity of epilepsy), psychosocial and iatrogenic (antiepileptic drugs, surgery) [17].

On the other hand, different factors were reported as significant factors for co-existence of depression and anxiety disorder among epileptic people. Female gender, frequent seizures, perceived stigma, low schooling, suicidal thought, or attempt, poly therapy and poor seizure control were risk factors for anxiety disorders $[10,12,13,16]$. Similarly, having frequent seizure, head trauma, perceived stigma, lower educational level, suicidality $[12,13]$, male gender, being married, low socio economic status, uncontrolled seizure and poly therapy were significantly associated with depression [15].

There are limited studies which showed the magnitude of depression and anxiety among epileptic patients in Sub-Saharan region particularly in Ethiopia. The aim of this study was to determine the magnitude of depression and anxiety disorders among epileptic people at Amanuel Mental Specialized Hospital, Ethiopia. Hence, the findings might have importance to stakeholders and policy makers working in NeuroPsychiatric areas by showing its prevalence and the factors associated with it.

\section{Methods}

\section{Study settings and population}

A cross sectional study design was conducted at Amanuel Mental Specialized Hospital (AMSH) in Addis Ababa from April to May, 2013. AMSH is one of oldest hospitals established in 1937 and located in western part of Addis Ababa, the capital city of Ethiopia. Ethiopia is the secondmost populous country in Sub-Saharan Africa with a population of more than 85 million people. It is an agrarian country and agriculture accounts for 43 percent of the gross domestic product. Primary health service coverage has reached $93 \%$ with 127 hospitals, 3,245 health centers, 16,048 health posts and more than 4,000 private for profit and not for profit clinics [18]. In Ethiopia, epilepsy is often mistakenly seen as a form of mental illness by the community and is usually treated by psychiatrists and psychiatric nurses. The most prescribed antiepileptic drugs were phenobarbitone, phenytoin and sometimes carbamazepine and sodium valproate. The hospital gives service for approximately 1200 epileptic patients per month.

The Study population was epileptic patients who had treatment follow up at outpatient department during study period. Patients aged 18 years and above with diagnosis of epilepsy and under treatment with one or more antiepileptic drugs from the outpatient units for at least 6 months were included in the study. Patients with serious general medical condition and unable to communicate were excluded.

\section{Sample size and sampling procedures}

The sample size for the study was calculated using the formula $[n=((z \alpha / 2) 2 \mathrm{p}(1-\mathrm{p})) / \mathrm{d} 2]$ for estimating a single population proportion at $95 \%$ confidence interval (CI) $(Z \alpha / 2=1.96), 5 \%$ margin of error. Due to absence of data in the country; proportion of population living with epilepsy and who had depression and anxiety was assumed to be $50 \%$, and by adding $10 \%$ contingency for non response rate, a total of 423 study populations were involved.

Systematic sampling method was used to select study population coming to AMSH during the study period from 1200 epileptic people. AMSH has 13 outpatient departments from which two of them are neurologic clinics. Sampling interval was determined by dividing total study population who had follow up during one month data collection period (1200) by total sample size (423).The sampling fraction is: 1200 / $423 \approx 3$. The first individual was selected by lottery method, and the next respondent was chosen at regular intervals (every $3^{\text {rd }}$ ) by data collectors.

\section{Data collection and quality control}

The data was collected using a pretested structured questionnaire developed in English and translated to 
Amharic and then to English by expertise and senior psychiatrist to ensure its consistency. The questionnaire was pre-tested on $5 \%$ of the sample size at AMSH two days prior to data collection. The questionnaire included socio-demographic characteristics and clinical factors of epilepsy. Concerning co-morbid anxiety, depression and stigma, Hospital Anxiety and Depression Scale (HADS) and stigma scale were used, respectively. HADS is a 14item questionnaire, commonly used to screen for symptoms of anxiety and depression. The 14-items can be separated into two 7-item sub-scales for anxiety and depression. HADS scale was validated in Ethiopia and the internal consistency was 0.78 for the anxiety, 0.76 for depression subscales and 0.87 for the full scale. The scales use a cut -off score for anxiety and depression of greater than or equal to 8 [19]. Felt stigma was assessed by three-item stigma scale which is validated at Zambia and comprised of dichotomous questions in which a positive response is indicative of felt or perceived stigma with an overall possible score ranging from 0 (no felt stigma) to 3 (maximally felt stigma) [20]. Data was collected by three trained diploma psychiatry nurses and one supervisor (BSc nurse) for a period of one month. Face to face interview was employed using local Amharic language.

Two days training was given to orient data collectors and supervisor on the questionnaire to be used, the purpose of the study and how to approach respondents and obtain consent. The data collectors were supervised daily and the filled questionnaires were checked for completeness and consistency by supervisor and principal investigator.

\section{Data management and analysis}

The data was coded, checked, cleaned and entered into computers using software Epi Info version 3.5.4 and then exported into SPSS window version 20 for analysis. Frequency, percentage, median were used to describe relevant variables using tables and graphs. Logistic regression was performed to assess the association between binary outcomes and different explanatory variables. Bivariate analysis was first conducted for each potentially explanatory risk factor. Variables that satisfied $p$-value $<0.2$ were selected for further analysis using multivariate logistic regression analysis in order to control confounding effects.

The strength of association was interpreted using odds ratio (OR) and confidence interval (CI). $P$-value $<0.05$ was considered statistically significant in this study.

\section{Ethical consideration}

Ethical clearance was obtained from University of Gondar and AMSH. Informed consent was obtained from the respondents. They were given the right to refuse to take part in the study as well as to withdraw at any time during the interview process. Confidentiality was maintained throughout the study.

\section{Results}

Socio-demographic characteristics of the respondents

Of the total 423 study participants enrolled, 415 were interviewed yielding a response rate of $98 \%$. Respondents' age ranged from 18 to 72 years with a median age of 28 years. Around fifty five percent of the respondents were males. Of the total respondents, $42.7 \%$ were in the age group of $25-$ 34 years. Majority of the respondents were single (61.4 \%), urban dwellers (84.6 \%), orthodox followers $(67.0 \%)$, having job (78.1\%), and Amhara (38.1\%) followed by Oromo (29.2 \%) by ethnicity. Regarding educational status, $37.6 \%$ attended secondary school followed by primary school (36.4 \%) (Table 1).

\section{Clinical characteristics of the respondents}

Out of the total 415 respondents, $35.2 \%$ were with epilepsy for five years followed by eleven years and above (34.2\%). Concerning age at onset of illness, $38.8 \%$ found between 10-19 years and 20-29 years (35.4\%). Most of the respondents ( $54.9 \%$ ) had one or more seizure attacks per month, under monotherapy (single antiepileptic drug) $(61.9 \%)$ and had no side effects of antiepileptic drugs (52.5\%). Around forty percent of the respondents perceived that they were stigmatized by other people because of their illness (Table 2).

\section{Prevalence of depression and anxiety among epileptic patients}

The prevalence of anxiety symptoms among epileptic patient was found to be $33.5 \%$ whereas prevalence of depression was 32.8 \% (Fig. 1).

Factors associated with co-morbid anxiety and depression On bivariate analysis, the factors found to fulfill the minimum requirement ( $p$-value $<0.2$ in this study) were age, marital status, educational level, occupation, monthly income, frequency of seizure, types of drugs, side effects of antiepileptic drugs (AEDs) and perceived stigma. However, no significant association was noted in depression and anxiety between males and females among epilepsy patients. Moreover, no differences were found among study variables like residence, duration of illness, both ever and current use of psychoactive substance at minimum requirement.

The results of multivariate logistic regression showed that monthly income, frequency of seizure and side effects of AEDs were significantly associated with both depression and anxiety. However, being divorced/ widowed was significantly associated with anxiety where as perceived stigma, types of AEDs, and unable to read and write were associated with depression. 
Table 1 Distribution of respondents by socio-demographic characteristics at AMSH, Addis Ababa, $2013(n=415)$

\begin{tabular}{|c|c|c|c|}
\hline Variable & & Number & Percentage (\%) \\
\hline \multirow[t]{2}{*}{ Sex } & Male & 229 & 55.2 \\
\hline & Female & 186 & 44.8 \\
\hline \multirow[t]{4}{*}{ Age } & $18-24$ & 130 & 31.3 \\
\hline & $25-34$ & 177 & 42.7 \\
\hline & $35-44$ & 68 & 16.4 \\
\hline & $45+$ & 40 & 9.6 \\
\hline \multirow[t]{3}{*}{ Marital status } & Single & 255 & 61.4 \\
\hline & Married & 146 & 35.2 \\
\hline & Divorced/Widowed & 14 & 3.4 \\
\hline \multirow[t]{2}{*}{ Residence } & Urban & 351 & 84.6 \\
\hline & Rural & 64 & 15.4 \\
\hline \multirow[t]{4}{*}{ Religion } & Orthodox & 278 & 67.0 \\
\hline & Muslim & 84 & 20.2 \\
\hline & Protestant & 47 & 11.3 \\
\hline & All others & 6 & 1.4 \\
\hline \multirow[t]{5}{*}{ Ethnicity } & Amhara & 158 & 38.1 \\
\hline & Oromo & 121 & 29.2 \\
\hline & Gurage & 93 & 22.4 \\
\hline & Tigre & 26 & 6.3 \\
\hline & Others & 17 & 4.1 \\
\hline \multirow[t]{4}{*}{ Educational status } & Unable to write and read & 35 & 8.4 \\
\hline & Primary school & 151 & 36.4 \\
\hline & Secondary school & 156 & 37.6 \\
\hline & Diploma and above & 73 & 17.6 \\
\hline \multirow[t]{2}{*}{ Occupation } & With Job & 324 & 78.1 \\
\hline & Without Job & 91 & 21.9 \\
\hline \multirow{4}{*}{$\begin{array}{l}\text { Monthly income } \\
\text { (ETB) }\end{array}$} & $<200$ & 117 & 28.2 \\
\hline & $200-500$ & 110 & 26.5 \\
\hline & $501-1000$ & 103 & 24.8 \\
\hline & $>1000$ & 85 & 20.5 \\
\hline
\end{tabular}

It was found that lower educational level was significantly associated with depression. Being unable to read and write was four times $(\mathrm{AOR}=4.36,95 \% \mathrm{CI}: 1.33$, 14.21) more likely to have depression as compared to respondents with educational level of diploma and above.

The result indicated that patients who had low income were about four and three times more likely to have depression and anxiety, respectively as compared to patients who had high income ( $\mathrm{AOR}=4.14,95 \% \mathrm{CI}: 1.67$, 10.25 and $\mathrm{AOR}=3.01,95 \%$ CI: $1.52,5.96)$.

Frequency of seizure was another factor associated with both depression and anxiety. Those who had seizure frequency greater than or equal to one seizure/ month were three times and twice more likely to have
Table 2 Distribution of respondents by clinical factors at AMSH, Addis Ababa, $2013(n=415)$

\begin{tabular}{|c|c|c|c|}
\hline Variable name & & Frequency & Percent \\
\hline \multirow[t]{3}{*}{ Duration of illness } & $\leq 5$ years & 146 & 35.2 \\
\hline & 6-10years & 127 & 30.6 \\
\hline & $\geq 11$ years & 142 & 34.2 \\
\hline \multirow[t]{4}{*}{ Age at onset of illness } & $<10$ years & 53 & 12.8 \\
\hline & 10-19 years & 161 & 38.8 \\
\hline & 20-29 years & 147 & 35.4 \\
\hline & $\geq 30$ years & 54 & 13.0 \\
\hline \multirow[t]{3}{*}{ Frequency of seizure } & $\geq 1 /$ month & 229 & 54.9 \\
\hline & 1-3/year & 58 & 14.0 \\
\hline & $\begin{array}{l}\text { Seizure free for } \\
1 \text { year }\end{array}$ & 129 & 31.1 \\
\hline \multirow[t]{2}{*}{ Type of drugs } & One & 257 & 61.9 \\
\hline & $\geq$ two & 158 & 38.1 \\
\hline \multirow{2}{*}{$\begin{array}{l}\text { Side effects of Anti-epileptic } \\
\text { drugs (AEDs) }\end{array}$} & Yes & 197 & 47.5 \\
\hline & No & 218 & 52.5 \\
\hline \multirow[t]{3}{*}{ Medication duration } & $\leq 5$ years & 232 & 55.9 \\
\hline & $6-10$ years & 79 & 19.0 \\
\hline & $\geq 11$ years & 104 & 25.1 \\
\hline \multirow[t]{2}{*}{ Perceived stigma } & Yes & 169 & 40.7 \\
\hline & No & 246 & 59.3 \\
\hline \multirow[t]{2}{*}{ Ever use substance } & Yes & 53 & 12.8 \\
\hline & No & 362 & 87.2 \\
\hline \multirow[t]{2}{*}{ current use substance } & Yes & 29 & 7.0 \\
\hline & No & 386 & 93.0 \\
\hline
\end{tabular}

depression and anxiety as compared to patients with no seizure in one year period, respectively $(\mathrm{AOR}=3.55$, 95 \% CI: 1.82, 6.93 and AOR = 2.21, 95 \% CI: 1.28, 3.79).

Moreover, patients who perceived stigma were twice more likely to have depression as compared to patients who didn't perceived stigma (AOR $=1.77,95 \%$ CI: 1.07, 2.93). Similarly, patients who were taking two or more types of AEDs were twice more likely to have depression as compared to patients who were taking one type of AEDs (AOR $=1.85,95 \% \mathrm{CI}: 1.08,3.17)$. Regarding side effects of medication, those who had side effects of AEDs were around three times more likely to have co-morbid anxiety and depression $(\mathrm{AOR}=2.51,95 \% \mathrm{CI}$ : $1.60,3.94)$ and $\mathrm{AOR}=3.07,95 \% \mathrm{CI}: 1.80,5.21$, respectively) (Tables 3 and 4).

\section{Discussion}

In this study, the prevalence of anxiety among epileptic people was $33.5 \%$ and the prevalence of depression was $32.8 \%$. The prevalence of anxiety was in line with the study done in China (30 \%) and Brazil (33-39\%) [12, 14]. 


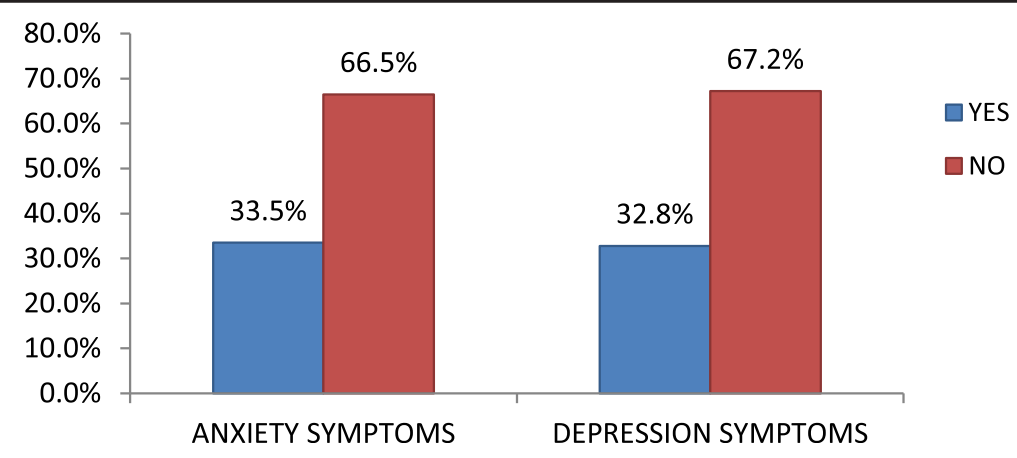

Fig. 1 Frequency of depression and anxiety symptoms among epileptic people attending at AMSH, 2013

However, in the present study, it was lower than the result reported from Thailand (39\%) and Egypt (47 \%) [10, 16]. The possible reason for the difference might be the inclusion criteria in Thailand were age between 15-50 years and could read and fill with self-administered questionnaire, while in Egypt there was instrument difference which is beck depression inventory and HAM-A and exclude any substance use, neurologic disease other than epilepsy.

The prevalence of depression (32.8\%) among epileptic people, in this study, is higher than the result (20\%) reported from Thailand [10] and lower than the result (60\%) in Pakistan [15]. Methodological issues might have contribution for differences found, for example, in

Table 3 Bivariate and multivariate analysis of variables associated with anxiety among epileptic patients at AMSH, Addis Ababa Ethiopia, $2013(n=415)$

\begin{tabular}{|c|c|c|c|c|c|}
\hline \multirow[t]{2}{*}{ Variable } & & \multicolumn{2}{|c|}{ Anxiety } & \multirow[b]{2}{*}{ COR(95 \% Cl) } & \multirow[b]{2}{*}{ AOR(95 \% Cl) } \\
\hline & & Yes & No & & \\
\hline \multirow[t]{3}{*}{ Marital status } & Married & 41 & 105 & 1 & 1 \\
\hline & Single & 88 & 167 & $1.39(0.86,2.10)$ & $1.22(0.75,1.96)$ \\
\hline & Divorced/widowed & 10 & 4 & $6.40(1.90,21.56)$ & $6.27(1.69,23.16)^{* *}$ \\
\hline \multirow[t]{4}{*}{ Education } & Unable to read \&write & 19 & 16 & $2.58(1.12,5.91)^{*}$ & $1.08(0.38,3.06)$ \\
\hline & primary school & 47 & 104 & $0.98(0.53,1.79)^{*}$ & $0.54(0.25,1.16)$ \\
\hline & Secondary school & 50 & 106 & $1.02(0.56,1.86)$ & $0.65(0.32,1.33)$ \\
\hline & Diploma \&above & 23 & 50 & 1 & 1 \\
\hline \multirow[t]{2}{*}{ Occupation } & With Job & 97 & 227 & 1 & 1 \\
\hline & Without Job & 42 & 49 & $2.00(1.24,3.22)^{*}$ & $1.14(0.61,2.14)$ \\
\hline \multirow[t]{4}{*}{ Monthly income } & $<200$ & 55 & 62 & $3.82(1.98,7.35)^{*}$ & $3.01(1.52,5.96)^{* *}$ \\
\hline & $200-500$ & 42 & 68 & $2.66(1.36,5.18)^{*}$ & $2.24(1.11,4.49)^{* *}$ \\
\hline & $501-1000$ & 26 & 77 & $1.45(0.72,2.93)^{*}$ & $1.44(0.68,3.04)$ \\
\hline & $>1000$ & 16 & 69 & 1 & 1 \\
\hline \multirow[t]{3}{*}{ Frequency of attack } & $\geq 1 /$ month & 96 & 132 & $2.88(1.74,4.77)^{*}$ & $2.21(1.28,3.79)^{* *}$ \\
\hline & 1-3/year & 17 & 41 & $1.64(0.80,3.34)^{*}$ & $1.41(0.67,2.99)$ \\
\hline & Seizure free/year & 26 & 103 & 1 & 1 \\
\hline \multirow[t]{2}{*}{ Type of drugs } & One & 66 & 191 & 1 & 1 \\
\hline & $\geq$ two & 73 & 85 & $2.48(1.63,3.78)^{*}$ & $1.49(0.91,2.46)$ \\
\hline \multirow[t]{2}{*}{ Side effects of AED } & Yes & 92 & 105 & $3.18(2.07,4.88)^{*}$ & $2.51(1.60,3.94)^{* *}$ \\
\hline & No & 47 & 171 & 1 & 1 \\
\hline \multirow[t]{2}{*}{ Perceived stigma } & Yes & 75 & 94 & $2.26(1.49,3.44)^{*}$ & 1.38(0.86,2.20) \\
\hline & No & 64 & 182 & 1 & 1 \\
\hline
\end{tabular}


Table 4 Bivariate and Multivariate analysis of variables associated with depression among epileptic people at AMSH, Addis Ababa Ethiopia, $2013(n=415)$

\begin{tabular}{|c|c|c|c|c|c|}
\hline \multirow[t]{2}{*}{ Variable } & & \multicolumn{2}{|c|}{ Depression } & \multirow[b]{2}{*}{ COR(95 \% Cl) } & \multirow[b]{2}{*}{ AOR(95 \% Cl) } \\
\hline & & Yes & No & & \\
\hline \multirow[t]{4}{*}{ Age } & $18-24$ & 30 & 100 & $0.79(0.35,1.76)$ & $0.75(0.25,2.17)$ \\
\hline & $25-34$ & 66 & 111 & $1.56(0.73,3.34)$ & $2.29(0.83,6.31)$ \\
\hline & $35-44$ & 29 & 39 & $1.96(0.84,4.56)$ & $2.29(0.76,6.87)$ \\
\hline & $45+$ & 11 & 29 & 1 & 1 \\
\hline \multirow[t]{4}{*}{ Education } & Unable to read \&write & 21 & 14 & $6.92(2.80,17.09)^{*}$ & $4.36(1.33,14.21)^{* *}$ \\
\hline & primary school & 48 & 103 & $2.15(1.07,4.29)^{*}$ & $1.44(0.61,3.40)$ \\
\hline & Secondary school & 54 & 102 & $2.44(1.23,4.84)$ & $2.52(0.90,5.81)$ \\
\hline & Diploma \&above & 13 & 60 & 1 & 1 \\
\hline \multirow[t]{2}{*}{ Occupation } & With Job & 93 & 231 & 1 & 1 \\
\hline & Without Job & 43 & 48 & $2.22(1.38,3.58)^{*}$ & $1.25(0.62,2.54)$ \\
\hline \multirow[t]{4}{*}{ Monthly income } & $<200$ & 52 & 65 & $5.38(2.59,11.17)^{*}$ & $4.14(1.67,10.25)^{*}$ \\
\hline & $200-500$ & 44 & 66 & $4.48(2.14,9.39)^{*}$ & $4.17(1.69,10.24)^{* *}$ \\
\hline & $501-1000$ & 29 & 74 & $2.63(1.22,5.66)^{*}$ & $3.34(1.37,8.10)^{* *}$ \\
\hline & $>1000$ & 11 & 74 & 1 & 1 \\
\hline \multirow[t]{3}{*}{ Frequency of attack } & $\geq 1 /$ month & 104 & 124 & $5.92(3.30,10.63)^{*}$ & $3.55(1.82,6.93)^{* *}$ \\
\hline & 1-3/year & 16 & 42 & $2.69(1.23,5.85)^{*}$ & $1.83(0.76,4.41)$ \\
\hline & Seizure free/year & 16 & 113 & 1 & 1 \\
\hline \multirow[t]{2}{*}{ Type of drugs } & One & 57 & 200 & 1 & 1 \\
\hline & $\geq$ two & 79 & 79 & $3.50(2.28,5.38)^{*}$ & $1.85(1.08,3.17)^{* *}$ \\
\hline \multirow[t]{2}{*}{ Side effects of AED } & Yes & 97 & 100 & $4.45(2.85,6.94)^{*}$ & $3.07(1.80,5.21)^{* *}$ \\
\hline & No & 39 & 179 & 1 & 1 \\
\hline \multirow[t]{2}{*}{ Perceived stigma } & Yes & 78 & 91 & $2.77(1.82,4.23)^{*}$ & $1.77(1.07,2.93)^{* *}$ \\
\hline & No & 58 & 188 & 1 & 1 \\
\hline
\end{tabular}

Note: ${ }^{*} P<0.2{ }^{* * P}<0.05$

Thailand; only those who could read and communicate were included. Education is one of the associated factors of depression as indicated in our study which is also in line with study done in Jimma [19]. Furthermore, the difference in sampling procedures and diagnostic instrument for depression and anxiety (different scales) might have a role for the variation.

Different studies indicated that people with low economic status and participants in low educational level had a higher risk of depression and anxiety [21-23]. The results of these studies are consistent with our study.

Regarding clinical factors, side effects of AEDs and frequency of seizure were associated with co-morbid depression and anxiety in this study. People who had side effects of medication and frequent seizure were found to have depression and anxiety as compared to people who had no side effects of medication and no seizure. This finding was consistent with many previous studies [9, 24].

The results of the present study also revealed that depression is significantly influenced by felt stigmatization about their epilepsy; which is in line with study done in Mangalore city of south India [25].

The strength of this study is the first of its kind in Ethiopia that determined the prevalence and associated factors for both depression and anxiety among epileptic patients. However, our limitations include recall bias regarding duration of illness, age at the onset of seizure and medication duration. Some important variables such as intellectual disability and treatment adherence were not assessed.

\section{Conclusion}

The prevalence of co-morbid anxiety and depression was found to be high among epileptic people in this study. Unable to read and write, low monthly income, frequent attacks of seizure, treatment with two or more drugs, side effects of AEDs and perceived stigma were significantly associated with co-morbid anxiety and depression. Clinicians and neurologists should early identify co-morbid psychiatric illnesses like depression and anxiety in people with 
epilepsy and it should be of great concern for health care providers. Further research should be done in different part of the country to provide stronger evidence regarding the prevalence and factors associated with this co-morbid anxiety and depression among epileptic people.

\section{Competing interests}

The authors declare that they have no competing interests.

\section{Authors' contribution}

MT, TB \& AA conceived and designed study; MT collected, analyzed and interpreted data; MT, TB, AA, AM, BT \& DA drafted the manuscript for important intellectual content. All authors read the draft manuscript and approved the final copy for submission.

\section{Acknowledgements}

This study received financial support from University of Gondar and AMSH. We would like to thank the staffs of AMSH for their cooperation during the study. We are also grateful to the study participants without whom the current study would not have been realized.

\section{Author details}

${ }^{1}$ College of Medicine and Health Science, Bahir Dar University, Bahir Dar, Ethiopia. ${ }^{2}$ College of Health Science, Nursing Department, Psychiatry Unit, Mekelle University, Mekelle, Ethiopia. ${ }^{3}$ College of Public Health and Medical Sciences, Department of Nursing, Jimma University, Jimma, Ethiopia. ${ }^{4}$ Amhara National Regional State Health Bureau, Bahir Dar, Ethiopia. ${ }^{5}$ Debre-Birhan Referral Hospital, Debre-Birhan, Ethiopia.

Received: 4 December 2014 Accepted: 14 August 2015

Published online: 02 September 2015

\section{References}

1. $\mathrm{WHO}$. Epilepsy in the $\mathrm{WHO}$ eastern Mediterranean region: Bridging the gap. 2010.

2. Epilepsy Action Australia. Understanding Epilepsy. 2008. Available at: http://www.epilepsy.org.au/understanding_epilepsy.asp

3. Epilepsy Action Australia. Epilepsy Explained. 2008. Available at: http://www.epilepsy.org.au/epilepsy_explained2.asp\#1

4. Kaplan \& Sadock. Synopsis of Psychiatry, 2007; $10^{\text {th }}$ edition. 527-528 and 580-582

5. Sadock BJ, Sadock VA, Ruiz P. Kaplan and Sadock's Comprehensive Textbook of Psychiatry, 9th Edition. 2009. p. 1840-4.

6. Jackson M, Turkington D. Depression and Anxiety in Epilepsy. J Neurol Neurosurg Psychiatry. 2005:76(Suppl I):i45-7.

7. Epilepsy Action Australia. Seizure Smart - a question of risk: life, death and epilepsy. 2011. Available at www.epilepsy.org.au. (accessed on September, 2014)

8. Ekinci O, Titus J, Rodopman A, Berkem M, Trevathan E. Depression and anxiety in children and adolescents with epilepsy: prevalence, risk factors, and treatment. Epilepsy Behav. 2009;14:8-18.

9. Kwon OY, Park SP. Depression and anxiety in people with epilepsy. J Clin Neurol. 2014;10(3):175-88.

10. Phabphal K, Sattawatcharawanich S, Sathirapunya P, Limapichart K. Anxiety and depression in Thai epileptic patients. J Med Assoc Thai. 2007;90(10):2010-5.

11. Arora H, Kaur R. Prevalence of depression in epileptic patients. Delhi Psychiatry J. 2009;12(2):231-3.

12. Stefanello S, Marín-Léon L, Fernandes PT, Li L, Botega NJ. Depression and anxiety in a community sample with epilepsy in Brazil. Arq Neuropsiquiatr. 2011:69(2-B):342-8

13. Pedroso de Souza EA, Salgado PB. A psychosocial view of anxiety and depression in epilepsy. Science Direct. Epilepsy Behav. 2006;8:232-8.

14. Kwan P, Yu E, Leung H, Leon T, Mychaskiw MA. Association of subjective anxiety, depression and sleep disturbance with quality of life in adults with epilepsy. Eilepsia. 2009;50(5):1059-66.

15. Yousafzai AR, Yousafzai AW, Taj R. Frequency of depression in epilepsy: a hospital based study. J Ayub Med Coll Abbottabad. 2009;21(2):73-5.
16. Hamed SA, Metwaly NH, Hassan MM, Mohamed KA, Ahmed MA, Soliman AA, et al. Depression in adults with epilepsy: Relationship to psychobiological variables. World J Neurol. 2012;2(1):1-10.

17. Marsh L, Rao V. Psychiatric complications in patients with epilepsy: a review. Epilepsy Res. 2002;49:11-33.

18. Federal Ministry of Health. Health and health related indicators of 2012/ 2013, Version 2. 2014.

19. Reda AA. Reliability and validity of the Ethiopian version of the Hospital Anxiety and Depression Scale (HADS) in HIV infected patients. PLoS One. 2011;6(1), e16049.

20. Baskind R, Birbeck GL. Epilepsy-associated stigma in sub-Saharan Africa: the social landscape of a disease. Epilepsy Behav. 2005;7:68-73.

21. Asadi-Pooya AA, Sperling MR. Depression and anxiety in patients with epilepsy, with or without other chronic disorders. Iran Red Crescent Med J. 2011;13(2):112-6

22. Prina AM, Ferri CP, Guerra M, Brayne C, Prince M. Co-occurrence of anxiety and depression amongst older adults in low- and middle-income countries: findings from the 10/66 study. Psychol Med. 2011;41(10):2047-56.

23. Lemstra M, Neudorf C, D'Arcy C, Kunst A, Warren LM, Bennett NR. A systematic review of depressed mood and anxiety by SES in youth aged 10-15 years. Can J Public Health. 2008;99:125-9.

24. Tsegabrhan H, Negash A, Tesfay K, Abera M. Co-morbidity of depression and epilepsy in Jimma University specialized hospital, Southwest Ethiopia. Neurol India. 2015;62:649-55.

25. Joseph N, Ray A, Reshma BK, Bhat S, Herady M, Kumar A. Assessment of quality of life, stigma associated and self-management practices among patients suffering from epileptic seizures: a cross sectional study. J Neurosci Behav Health. 2011;3(7):91-8.

\section{Submit your next manuscript to BioMed Central and take full advantage of:}

- Convenient online submission

- Thorough peer review

- No space constraints or color figure charges

- Immediate publication on acceptance

- Inclusion in PubMed, CAS, Scopus and Google Scholar

- Research which is freely available for redistribution 